\title{
Replicative random mutations as an unproven cause of cancer: A technical comment
}

\author{
DOMINIQUE BELPOMME ${ }^{1,2}$ and PHILIPPE IRIGARAY ${ }^{1,2}$ \\ ${ }^{1}$ Cancer Research Center, Association for Research and Treatments Against Cancer (ARTAC), F-75015 Paris, France; \\ ${ }^{2}$ European Cancer and Environment Research Institute (ECERI), B-1000 Brussels, Belgium
}

Received July 31, 2015; Accepted December 8, 2015

DOI: $10.3892 / \mathrm{mco} .2016 .737$

\begin{abstract}
A careful molecular biology, epidemiological and mathematical modelling reanalysis of the recently published study titled 'Cancer etiology. Variation in cancer risk among tissues can be explained by the number of stem cell divisions' by Cristian Tomasetti and Bert Vogelstein, which was published on January 2, 2015 in the distinguished journal Science, led to the conclusion that, contrary to the authors' claim, many cancer types are not caused by replicative random mutations. Rather than the authors' two arbitrarily individualized groups of cancer, a three-group model is herein proposed in the framework of this technical comment, considerably reducing the fraction of cancer cases hypothetically attributable to random mutations.
\end{abstract}

\section{Technical comment}

After reading the paper by Cristian Tomasetti and Bert Vogelstein (1) and the following comments, including those from the World Health Organization International Agency for Cancer Research (Lyon, France) and the Collegium Ramazzini in Italy (2-10), we herein present a molecular biology, epidemiological and mathematical modeling reanalysis that strongly disagrees with their conclusion, stating that several cancer types may be caused by random somatic mutations arising during DNA replication of normal stem cells. Instead of the author's two-group individualized model, a three-group model is proposed, considerably reducing the fraction of cancer hypothetically attributable to random mutations.

The hypothesis that the lifetime risk of cancer differs according to tissue type due to the different total number of

Correspondence to: Mr. Philippe Irigaray, Cancer Research Center, Association for Research and Treatments Against Cancer (ARTAC), 57-59 Rue de la Convention, F-75015 Paris, France

E-mail: philippei.artac@gmail.com

Abbreviations: $\mathrm{D}$, deterministic; $\mathrm{R}$, replicative; $\mathrm{R}^{2}$, coefficient of determination

Key words: carcinogenesis, cancer, mutagens, environment, mutations, epidemiology divisions of stem cells in normal tissues, is coherent with our knowledge on carcinogenesis, since, according to the somatic mutation theory, cancer is associated with mutations $(11,12)$ and cell divisions are required for mutations to occur (13).

However, carcinogenesis is a multistep, multifactorial process, with etiological factors other than the natural proliferative rate of normal tissue (14). While random mutations, which may occur in addition to deterministic events during the whole process of carcinogenesis, are well known, this is more problematic when applied to cancer initiation.

Cancer may result from gene-environment interactions mediated by epigenetic mechanisms (15); thus, in addition to innate or acquired hereditary susceptibility factors, clearly exogenous factors such as chemicals, radiation and/or microorganisms, play a key role in carcinogenesis directly, by interfering with DNA, and/or indirectly, through epigenetic pathways (16-18).

Moreover, it has been estimated that stochastic mutations, referred to as spontaneous somatic point mutations, may be in the order of $10^{-5}$ to $10^{-3}$ per sexual generation for the entire genome of eukaryotic cells (19), and these mutations are not randomly distributed within the eukaryotic genome, but mainly in its non-coding nucleosome-depleted part (20). It is unlikely that random mutations at this rate may cause cancer initiation and account for cancer occurrence that is at present significantly more frequent than 1 case out of 1,000. In fact, as random mutations mainly encompass somatic point mutations rather than cancer-causing (clonogenic) driver mutations, and cancer results from several driver mutations (15), random mutation-related cancer should be much less frequent yet.

We therefore analyzed from the standpoint of epidemiology the authors' different cancer types in the so called replicative ( $\mathrm{R})$ stochastic group. As depicted in Fig. 1, apart from pancreatic cancer, all $\mathrm{R}$ group cancers have been shown to be associated with an increased incidence over the last 3 or 4 decades in the USA (21), as well as in Europe (22). We disagree with Tomasetti's response to our question, that 'the fact that cancer incidence has increased over the last 3-4 decades may be explained in part as a consequence of random replicative mutations, given the longer lifespan of the population' and that 'an increase in screening and awareness certainly played a role in the increase in the observed incidence of melanoma, as well as that of many other cancers'. These arguments are not convincing, since cancer may be initiated 
A

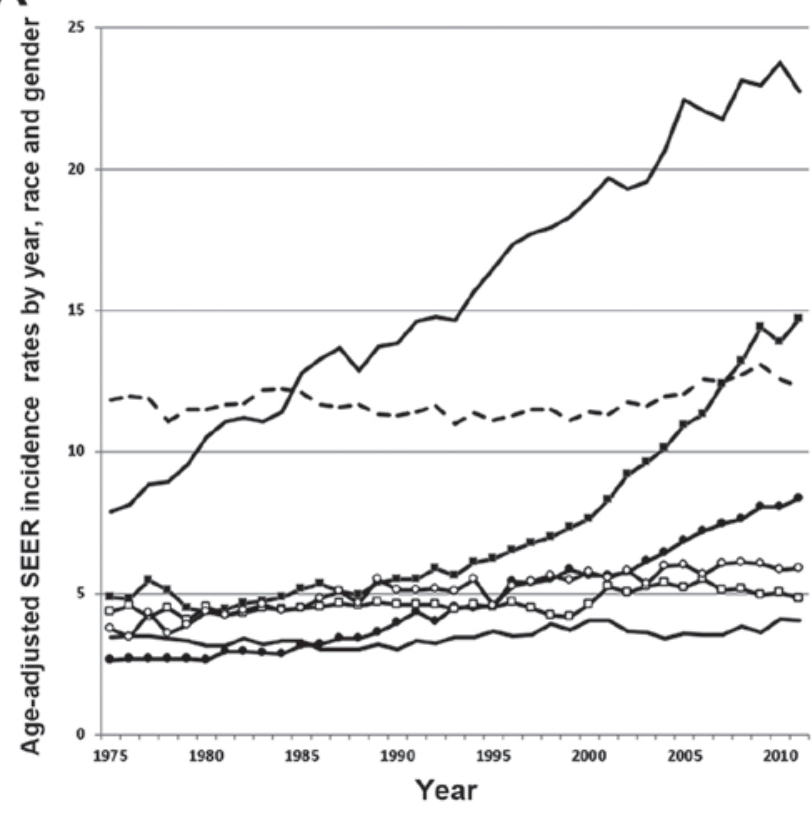

B

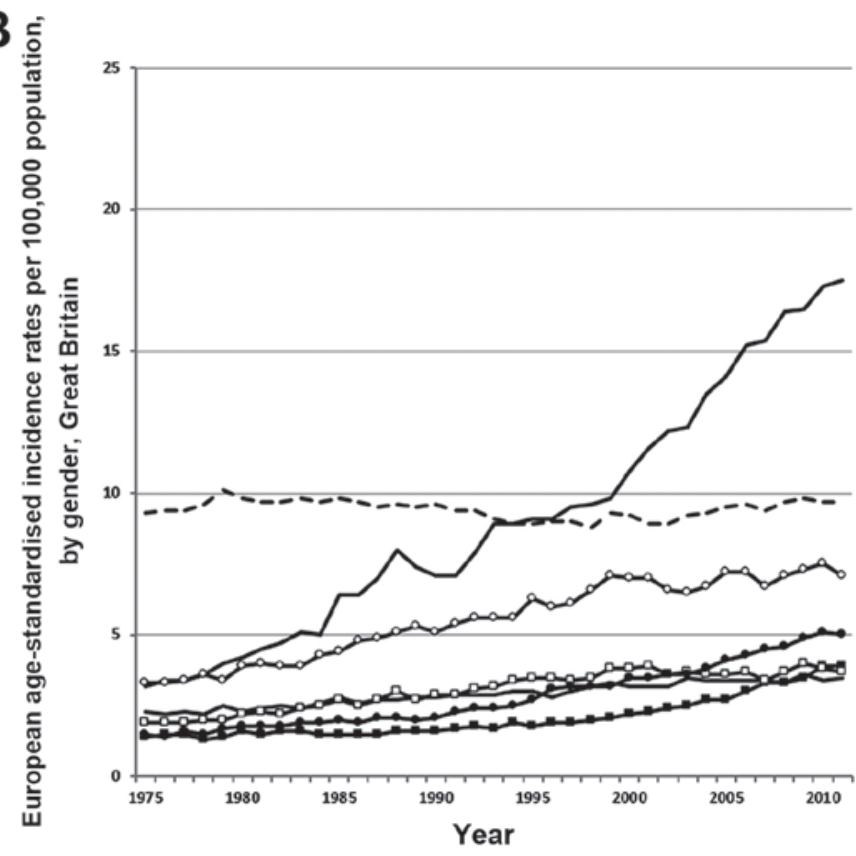

Figure 1. Cancer incidence for cancers of the R group in (A) the USA and (B) Europe. SEER, Surveillance, Epidemiology and End Results Program.

A

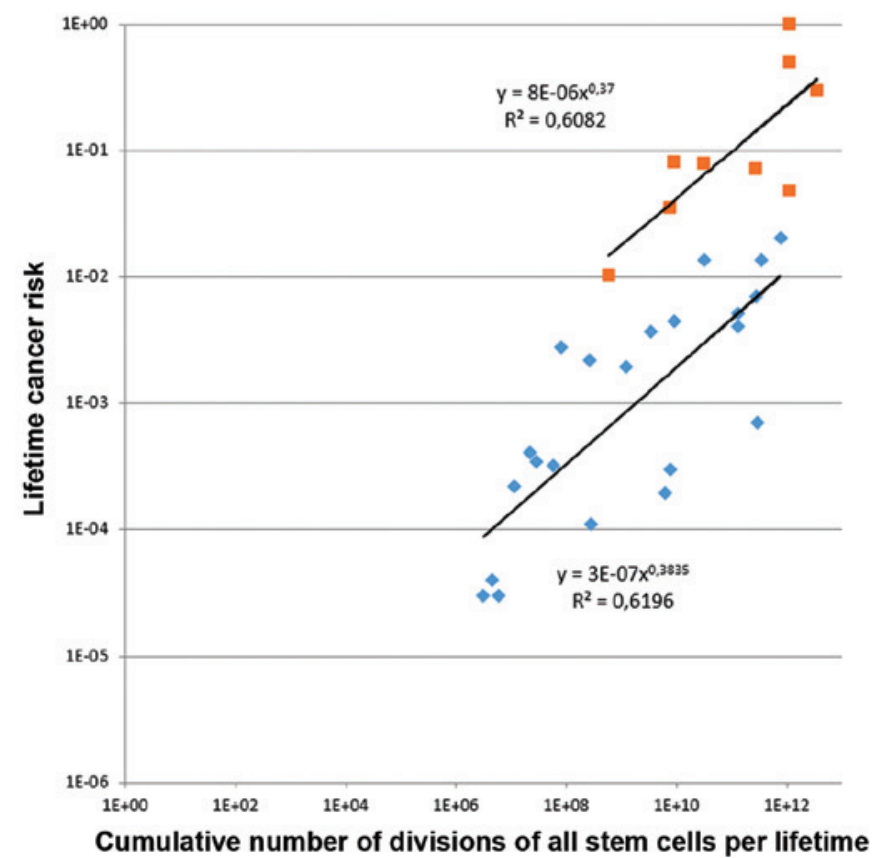

B

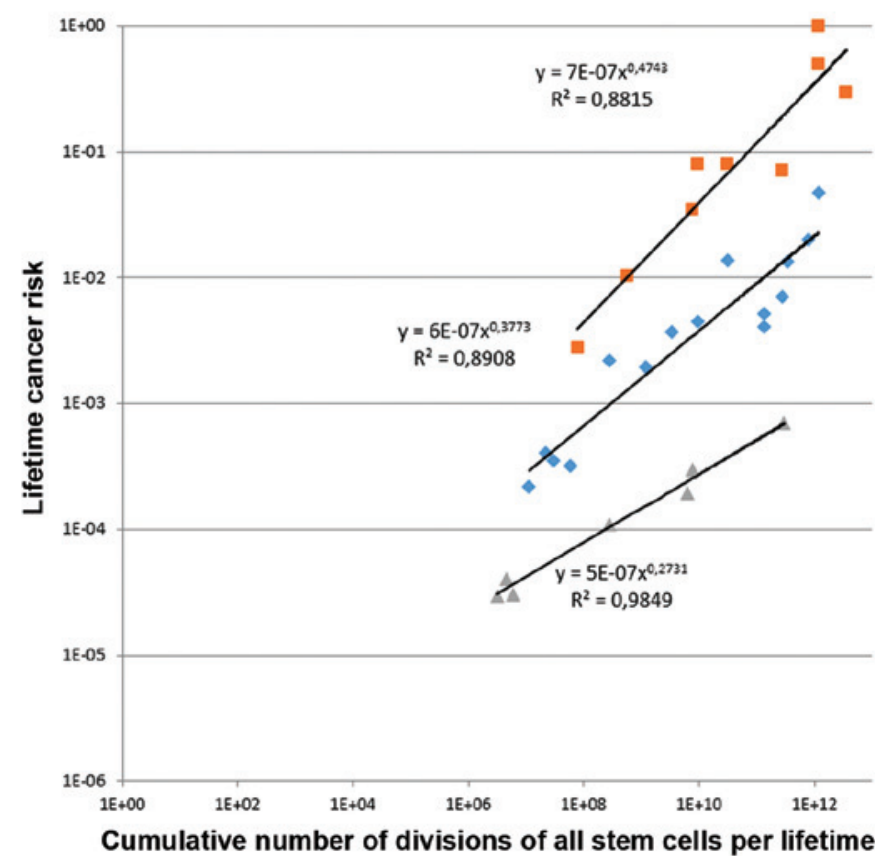

Figure 2. Calculation of the linear regression coefficient $\left(R^{2}\right)$ for the two (R and D) groups as determined from (A) Figs. 1 and 2 of Tomasetti and Vogelstein, and (B) our proposal for a three-group model.

at the fetal stage (23), increased cancer incidence concerns all age categories, and screening by itself cannot account for the 'continuous' increased incidence of several cancer types, including those which cannot be screened $(24,25)$. We therefore concluded that the stochastic interpretation attributed to the author's R group is not consistent with current epidemiological and biological data.
Taking into account the supplementary material of the article, we investigated the mathematical method that Tomasetti and Vogelstein used to define their two groups, R and deterministic (D), the basis of their claim. Considering the association between the lifetime cancer risk and the total number of stem cell divisions (Fig. 1A), a strong correlation at 0.804 was demonstrated statistically by using the Pearson's 
Chi-square test. However, applying a linear regression test, we obtained a coefficient of determination, denoted $\mathrm{R}^{2}$, of only 0.6463 , indicating that a soundly established linear relation is unlikely. Moreover, we combined Figs. 1 and 2 of the authors' article in a single figure for the purpose of simplification and better understanding, and estimated $\mathrm{R}^{2}$ for each of the arbitrarily individualized $\mathrm{R}$ and $\mathrm{D}$ groups. Again, we found the same order of $\mathrm{R}^{2}$ (Fig. 2A), confirming that linearity is not clearly established. We therefore tentatively individualized a third group from the $\mathrm{R}$ and $\mathrm{D}$ initial groups. As indicated in Fig. 2B, we observed a significantly improved linear regression, with $\mathrm{R}^{2}$ of $0.88,0.89$ and 0.98 for the newly individualized $\mathrm{D}$, intermediate and $\mathrm{R}$ groups, respectively. This suggests that, when restricting the $\mathrm{R}$ group to a significantly smaller number of cancer types, the intermediate group may in fact include both stochastic and deterministic events, a hypothesis which appears to be more coherent with what we previously discussed. Although a very small proportion of cancers may be caused by spontaneous random mutations, we strongly suggest that the scientific message of Tomasetti and Vogelstein does not agree with the currently available biological, epidemiological and toxicological data. The process of carcinogenesis has not been sufficiently taken into consideration, so the interpretation of Tomasetti's and Vogelstein's results may be hazardous, as it de-emphasizes highly needed primary prevention and limits it to for a small proportion of cancer types.

\section{References}

1. Tomasetti C and Vogelstein B: Cancer etiology. Variation in cancer risk among tissues can be explained by the number of stem cell divisions. Science 347: 78-81, 2015.

2. Couzin-Frankel J: Biomedicine. The bad luck of cancer. Science 347: 12, 2015.

3. Ashford NA, Bauman P, Brown HS, Clapp RW, Finkel AM, Gee D, Hattis DB, Martuzzi M, Sasco AJ and Sass JB: Cancer risk: Role of environment. Science 347: 727, 2015.

4. Potter JD and Prentice RL: Cancer risk: Tumors excluded. Science 347: 727, 2015.

5. Wild C, Brennan P, Plummer M, Bray F, Straif K and Zavadil J: Cancer risk: Role of chance overstated. Science 347: 728, 2015.

6. Gotay C, Dummer T and Spinelli J: Cancer risk: Prevention is crucial. Science 347: 728, 2015.

7. Song M and Giovannucci EL: Cancer risk: Many factors contribute. Science 347: 728-729, 2015.
8. O'Callaghan M: Cancer risk: Accuracy of literature. Science 347: $729,2015$.

9. Tomasetti C and Vogelstein B: Cancer risk: Role of environment-response. Science 347: 729-731, 2015.

10. Collegium Ramazzini. 17th position statement: Most types of cancer are cot due to bad luck. Available at: http://www.collegiumramazzini.org/download/17_SeventeenthCRStatement(2015). pdf. Accessed March 10, 2015

11. Sjöblom T, Jones S, Wood LD, Parsons DW, Lin J, Barber TD, Mandelker D, Leary RJ, Ptak J, Silliman N, et al: The consensus coding sequences of human breast and colorectal cancers. Science 314: 268-274, 2006.

12. Greenman C, Stephens P, Smith R, Dalgliesh GL, Hunter C, Bignell G, Davies H, Teague J, Butler A, Stevens C, et al: Patterns of somatic mutation in human cancer genomes. Nature 446: 153-158, 2007.

13. Weinstein IB: Mitogenesis is only one factor in carcinogenesis. Science 251: 387-388, 1991

14. Skinner MK, Manikkam M and Guerrero-Bosagna C: Epigenetic transgenerational actions of environmental factors in disease etiology. Trends Endocrinol Metab 21: 214-222, 2010.

15. Weinberg RA: The Biology of Cancer. 2nd edition. Garland Science, New York, NY, 2013.

16. Irigaray $\mathrm{P}$ and Belpomme D: Basic properties and molecular mechanisms of exogenous chemical carcinogens. Carcinogenesis 31: 135-148, 2010.

17. Elmore SA, Boyle MC, Boyle MH, Cora MC, Crabbs TA, Cummings CA, Gruebbel MM, Johnson CL, Malarkey DE, McInnes EF, et al: Proceedings of the 2013 National Toxicology Program Satellite Symposium. Toxicol Pathol 42: 12-44, 2014.

18. National Toxicology Program: 13th report on Carcinogens (2014). http://ntp.niehs.nih.gov/pubhealth/roc/roc13/index.html. Accessed January 12, 2015.

19. Drake JW, Charlesworth B, Charlesworth D and Crow JF: Rates of spontaneous mutation. Genetics 148: 1667-1686, 1998.

20. Chen X, Chen Z, Chen H, Su Z, Yang J, Lin F, Shi S and He X: Nucleosomes suppress spontaneous mutations base-specifically in eukaryotes. Science 333: 1235-1238, 2012.

21. National Cancer Institute, Surveillance, Epidemiology, and End Results Program. www.seer.cancer.gov. Accessed January 12, 2015.

22. Cancer Research UK. http://www.cancerresearchuk.org. Accessed January 12, 2015.

23. Marshall GM, Carter DR, Cheung BB, Liu T, Mateos MK, Meyerowitz JG and Weiss WA: The prenatal origins of cancer. Nat Rev Cancer 14: 277-1689, 2014.

24. Belpomme D, Irigaray P, Hardell L, Clapp R, Montagnier L, Epstein S and Sasco AJ: The multitude and diversity of environmental carcinogens. Environ Res 105: 414-429, 2007.

25. Belpomme D, Irigaray P, Sasco AJ, Newby JA, Howard V, Clapp R and Hardell L: The growing incidence of cancer: Role of lifestyle and screening detection. Int J Oncol 30: 1037-1044, 2007. 